\title{
Preparation of High Purity Lead Oxide from Spent Lead Acid Batteries via Desulphurization and Recrystallization in Sodium Hydroxide
}

\author{
Junqing Pan ${ }^{\mathrm{a},}$, Xuan Zhang ${ }^{\mathrm{a}}$, Yanzhi Sun ${ }^{\mathrm{b},{ }^{*} \text {, Shuang Song }}{ }^{\mathrm{a}, \mathrm{c}}$, Wei $\mathrm{Li}^{\mathrm{d}}$, Pingyu Wan ${ }^{\mathrm{b}}$ \\ ${ }^{a}$ State Key Laboratory of Chemical Resource Engineering, Beijing University of \\ Chemical Technology, Beijing 100029, China \\ ${ }^{b}$ National Fundamental Research Laboratory of New Hazardous Chemicals \\ Assessment and Accident Analysis, Beijing University of Chemical Technology, \\ Beijing 100029, China \\ ${ }^{c}$ Chilwee Power Group, Huzhou, Zhejiang Province, 313100, China \\ ${ }^{d}$ Department of Engineering Technology and Texas Center for Superconductivity, \\ University of Houston, Houston, TX 77204, USA \\ *Corresponding authors: \\ Tel./Fax: 8610-64448461; \\ E-mails: jqpan@mail.buct.edu.cn; sunyz@mail.buct.edu.cn.
}


According to the schematic diagrams of experimental setups in Figure S1, the stirring equipment is required during the catalytic conversion and desulfurization process, and the conversion and desulfurization temperatures can be controlled by a water bath. A crystallization system is needed during the recrystallization processes. The filtration is necessary during all the experiment processes, and the filter liquor (the residual $\mathrm{H}_{2} \mathrm{SO}_{4}$ ) after conversion process and the filter liquor (the solution of $\mathrm{NaOH})$ after the recrystallization processes are recycled and reused in the next cycle. Every experimental process takes place by wet procedures.

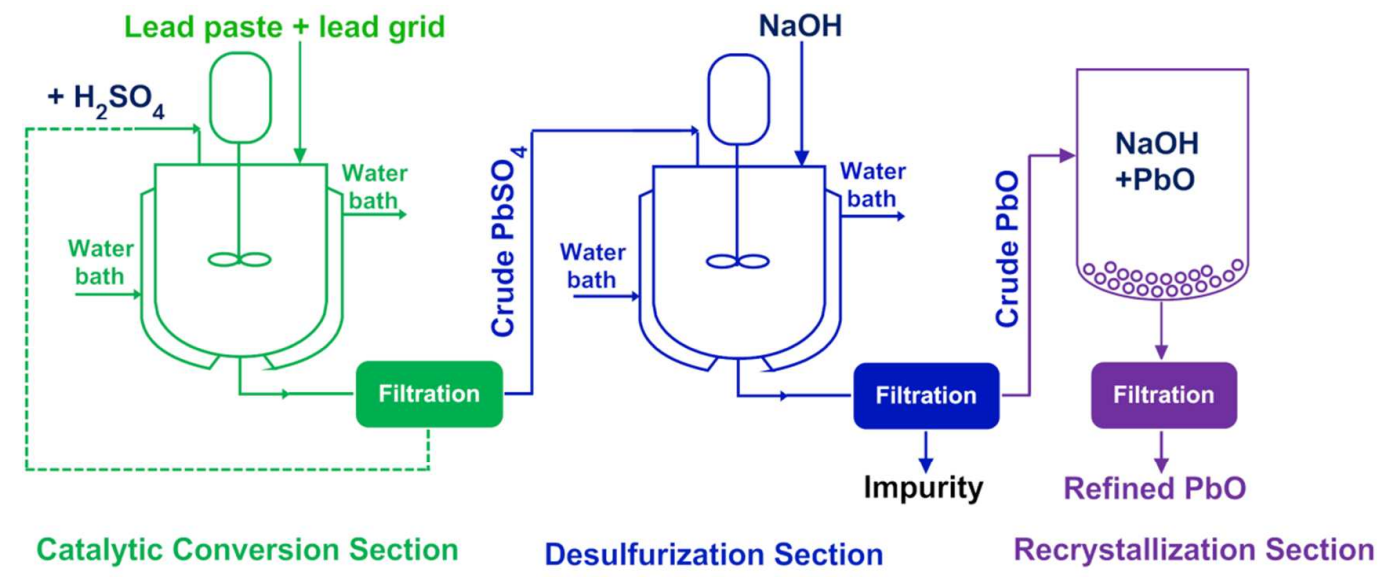

Figure S1 The schematic diagrams of catalytic conversion and desulfurization-recrystallization processes

Figures $\mathrm{S} 2$ and $\mathrm{S} 3$ show the photos of the reactions of $\mathrm{PbO}_{2}-\mathrm{Fe}^{2+}$ and $\mathrm{Fe}^{3+}-\mathrm{Pb}$ couples, respectively. As seen from Figure S2, $0.1 \mathrm{~mol} \mathrm{~L}^{-1} \mathrm{Fe}^{2+}$ solution was colorless (A1). The color of $\mathrm{Fe}^{2+}$ solution was unchanged when three drops of $0.1 \mathrm{~mol} \mathrm{~L}^{-1}$ KSCN (color agent) was added, which indicated there were no $\mathrm{Fe}^{3+}$ ions in the 
solution (A2). When $0.1 \mathrm{~g} \mathrm{PbO}_{2}$ was added to the solution, the solution turned into red immediately, indicating that $\mathrm{Fe}^{2+}$ has been oxidized into $\mathrm{Fe}^{3+}$. The $\mathrm{Fe}^{3+}$ was developed with $\mathrm{KSCN}$ (A3) and the color of solution became much darker after 3 min, which means more $\mathrm{Fe}^{3+}$ was generated by the oxidant of $\mathrm{PbO}_{2}$ (A4). The oxidation-reduction and chromogenic reactions are as follows:

(1) Redox process:

$$
\mathrm{PbO}_{2}+2 \mathrm{Fe}^{2+}+4 \mathrm{H}^{+}=\mathrm{Pb}^{2+}+2 \mathrm{Fe}^{3+}+2 \mathrm{H}_{2} \mathrm{O}
$$

(2) Chromogenic process:

$$
\mathrm{Fe}^{3+}+6 \mathrm{SCN}^{-}=\mathrm{Fe}(\mathrm{SCN})_{6}^{3-}
$$
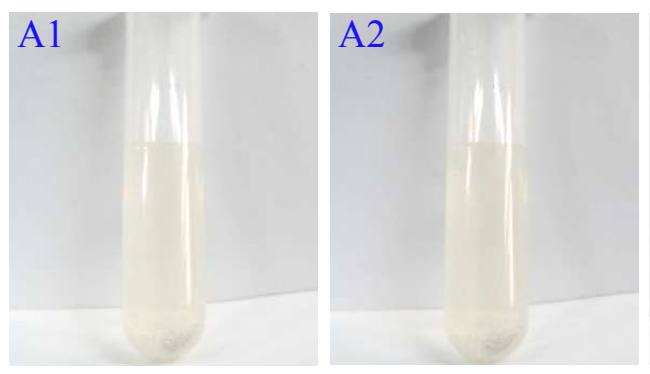

A3

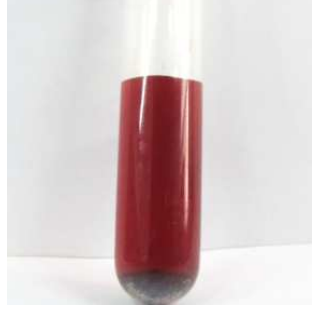

A4

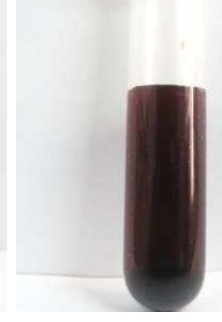

Figure $\mathrm{S} 2$ The photos of the reaction of $\mathrm{PbO}_{2}-\mathrm{Fe}^{2+}$ couple (A1, $0.1 \mathrm{~mol} \mathrm{~L}^{-1} \mathrm{Fe}^{2+}$ solution; $\mathrm{A} 2, \mathrm{Fe}^{2+}$ solution with 3 drops of $\mathrm{KSCN}\left(0.1 \mathrm{~mol} \mathrm{~L}^{-1}\right)$ as color reagent; $\mathrm{A} 3$, adding $0.1 \mathrm{~g} \mathrm{PbO}_{2}$; $\mathrm{A} 4$, aged for $3 \mathrm{~min}$ ).

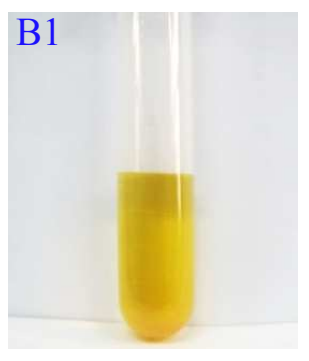

B2

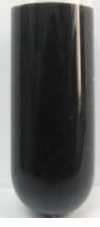

B3

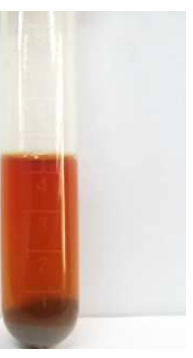

B4

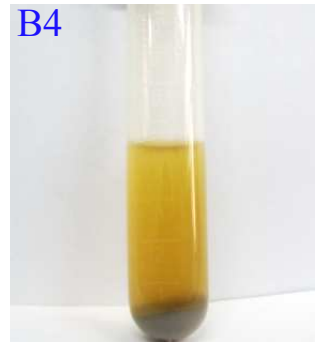

Figure $\mathrm{S} 3$ The photos of the reaction of $\mathrm{Fe}^{3+}-\mathrm{Pb}$ couple.

(B1, 0.1mol L $\mathrm{Fe}^{3+}$ solution; B2, $\mathrm{Fe}^{3+}$ solution with 3 drops of $\mathrm{KSCN}\left(0.1 \mathrm{~mol} \mathrm{~L}^{-1}\right)$ as color reagent; $\mathrm{B} 3$, adding $0.1 \mathrm{~g} \mathrm{~Pb}$ powders; $\mathrm{B} 4$, reacted for $3 \mathrm{~min}$ ). 
As seen from Figure $\mathrm{S} 3$, the original color of $\mathrm{Fe}^{3+}$ solution was present in yellow (B1). When 3 drops of $0.1 \mathrm{~mol} \mathrm{~L}^{-1} \mathrm{KSCN}$ was added to the $\mathrm{Fe}^{3+}$ solution, a chromogenic reaction occurred so that the color of solution turned into red immediately (B2). Then $0.1 \mathrm{~g} \mathrm{~Pb}$ powders as reductant was added to the above solution and red color was fading (B3). Finally, the red color of solution was vanished after 3 min (B4), which indicated that most of $\mathrm{Fe}^{3+}$ have transformed into $\mathrm{Fe}^{2+}$. The oxidation-reduction and chromogenic reactions of the above processes are as follows:

(1) Chromogenic process:

$$
\mathrm{Fe}^{3+}+6 \mathrm{SCN}^{-}=\mathrm{Fe}(\mathrm{SCN})_{6}^{3-}
$$

(2) Redox process:

$$
\mathrm{Pb}+2 \mathrm{Fe}^{3+}=\mathrm{Pb}^{2+}+2 \mathrm{Fe}^{2+}
$$

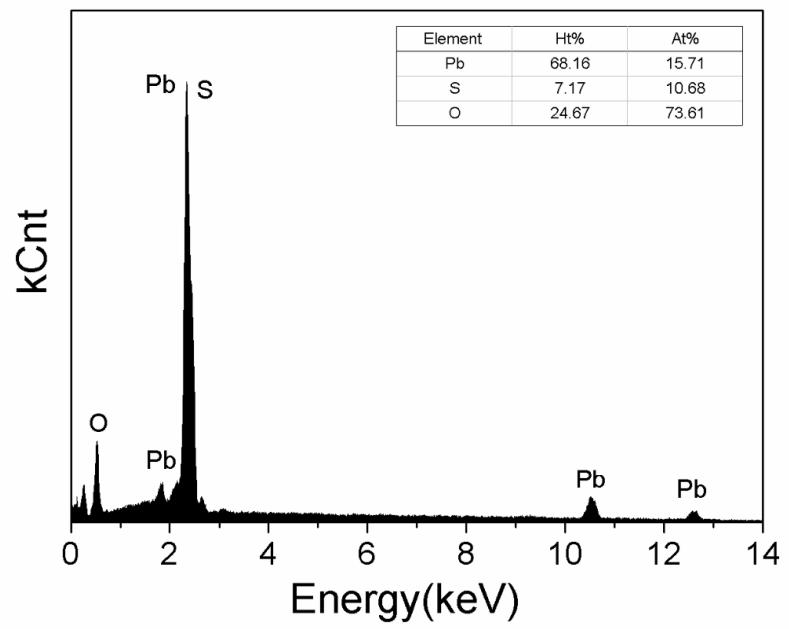

Figure S4 The EDS analyzing results of the obtained $\mathrm{PbSO}_{4}$.

The EDS analyzing results of the $\mathrm{PbSO}_{4}$ obtained from the catalytic conversion are shown in Figure S4. The EDS analysis is performed in order to confirm that the sample is mainly made of $\mathrm{Pb}, \mathrm{S}$ and $\mathrm{O}$ elements. It can been seen that the atom ratio 
of $\mathrm{Pb}: \mathrm{S}: \mathrm{O}=15.71: 15.67: 69.61$, which is approximate to the atom ratio of $1: 1: 4$, corresponding to $1 \mathrm{~Pb}: 1 \mathrm{~S}: 4 \mathrm{O}$, thus indicating the sample is $\mathrm{PbSO}_{4}$.

\begin{tabular}{ccccc}
\multicolumn{4}{c}{ Table S1The concentration of $\mathrm{Fe}^{2+}, \mathrm{Cl}^{-}, \mathrm{Pb}^{2+}$ and $\mathrm{H}_{2} \mathrm{SO}_{4}$ after each cycle } \\
\hline $\begin{array}{c}\text { Cycle } \\
\text { number }\end{array}$ & $\mathrm{Fe}^{2+} / \mathrm{mol} \mathrm{L}^{-1}$ & $\mathrm{Cl}^{-} / \mathrm{mol} \mathrm{L}^{-1}$ & $\mathrm{~Pb}^{2+} / \mathrm{mol} \mathrm{L}^{-1}$ & $\mathrm{H}_{2} \mathrm{SO}_{4} / \mathrm{mol} \mathrm{L}^{-1}$ \\
\hline 0 & 0.1032 & 0.1031 & 0.0000 & 2.200 \\
1 & 0.1025 & 0.1028 & 0.0018 & 1.082 \\
2 & 0.1009 & 0.1003 & 0.0022 & 1.074 \\
3 & 0.1011 & 0.0994 & 0.0025 & 1.078 \\
4 & 0.1005 & 0.0986 & 0.0024 & 1.080 \\
5 & 0.1019 & 0.0992 & 0.0023 & 1.077 \\
6 & 0.0997 & 0.0969 & 0.0025 & 1.118 \\
7 & 0.1009 & 0.0981 & 0.0025 & 1.088 \\
8 & 0.1002 & 0.0985 & 0.0023 & 1.079 \\
\hline
\end{tabular}

